\title{
Análise da Produção Científica na Revista ABCustos: a participação feminina de 2006 a 2016
}

Clayton Robson Moreira da Silva
Doutorado em andamento em Administração e Controladoria pela Universidade Federal
do Ceará - UFC
Professor do Instituto Federal de Educação, Ciência e Tecnologia do Piauí - IFPI
E-mail: claytonrmsilva@gmail.com

Laís Vieira Castro Oliveira Mestrado em andamento em Administração e Controladoria pela Universidade Federal do Ceará - UFC Professora do Instituto Federal de Educação, Ciência e Tecnologia do Piauí - IFPI E-mail: laisvieirac@hotmail.com

Cinthya Rachel Firmino de Morais Mestrado em andamento em Administração e Controladoria pela Universidade Federal do Ceará - UFC E-mail: cinthyarachelf@gmail.com

Diego Sampaio Vasconcelos Ramalho Lima Mestrado em andamento em Administração e Controladoria pela Universidade Federal do Ceará - UFC E-mail: diegolima_sampaio@hotmail.com

\section{RESUMO}

Este estudo teve o objetivo de analisar a participação feminina na produção científica sobre custos na Revista ABCustos. Adicionalmente, verificou-se o perfil dos artigos publicados no periódico. O estudo caracteriza-se como descritivo, tem abordagem qualitativa e quantitativa e foi conduzido um estudo bibliométrico. Foram analisados os 173 artigos publicados desde a primeira edição da Revista ABCustos. Utilizou-se técnica de análise de conteúdo no tratamento dos dados. Os resultados apontam que apenas 13 artigos têm autoria exclusivamente feminina; o arranjo mais comum do número de autores por artigo é em trio; o número de autoras é inferior ao número de autores; a região com maior número de autores que publicam no periódico é a Sul; a maior parte dos artigos utiliza abordagem qualitativa; a temática mais recorrente nos artigos é "Gestão de Custos"; a IES que tem o maior número de autores vinculados que publicam na ABCustos é a UNISINOS; e, por fim, a autora do gênero feminino que mais publica no periódico é llse Maria Beuren, porém há quatro autores do gênero masculino que apresentam maior volume de publicação do que ela.

Palavras-chave: Participação Feminina. Produção Científica. Custos. ABCustos. Bibliometria. 
Análise da Produção Científica na Revista ABCustos: a participação feminina de 2006 a 2016

Clayton Robson Moreira da Silva, Laís Vieira Castro Oliveira, Cinthya Rachel Firmino de Morais, Diego

Sampaio Vasconcelos Ramalho Lima

\section{Analysis of Scientific Production in ABCustos Journal: female participation from} 2006 to 2016

\section{ABSTRACT}

This study aimed to analyze the female participation in the scientific production on costs in ABCustos Journal. Additionally, the profile of the articles published in the journal was verified. The study is characterized as descriptive, it has qualitative and quantitative approach and it was conducted a bibliometric study. 173 articles that have been published since the first edition of ABCustos Journal were analyzed. Content analysis technique was used in the data treatment. Results show that only 13 articles have exclusively female authorship; the most common arrangement of the number of authors per article is in trio; the number of female authors is less than the number of male authors; the region with the highest number of authors who publish in the journal is the South; most articles use a qualitative approach; the most recurrent theme in the articles is "Cost Management"; The Higher Education Institution that has the largest number of related authors who publish in ABCustos is UNISINOS; and, finally, the female author who most publishes in the journal is Ilse Maria Beuren, but there are four authors of the masculine gender who present a greater volume of publication than she does.

Keywords: Female Participation. Scientific Production. Costs. ABCustos. Bibliometrics.

\section{INTRODUÇÃO}

A resistência da inserção de mulheres no âmbito social emerge em meio aos estereótipos conferidos ao gênero feminino. Nessa esteira, Silva, Anzilago e Lucas (2015) argumentam que a ausência das mulheres em posições de destaque é comumente justificada por alguns atributos que seriam inerentes ao sexo feminino, tais como: diferenças de conhecimento, motivação e personalidade. Esse contexto de construção social da figura feminina como indivíduo frágil e dependente pode levar ao desengajamento da mulher em ambientes profissionais, conduzindo-as a uma vida doméstica e centrada na família.

Nessa seara, discute-se que, por muitos anos, o papel da mulher na sociedade esteve limitado a atribuições domésticas, enquanto a apropriação do espaço público, o 
Análise da Produção Científica na Revista ABCustos: a participação feminina de 2006 a 2016 Clayton Robson Moreira da Silva, Laís Vieira Castro Oliveira, Cinthya Rachel Firmino de Morais, Diego

Sampaio Vasconcelos Ramalho Lima

sustento familiar e o poder decisório eram características exclusivamente inerentes ao gênero masculino. Porém, nos últimos tempos, o papel da mulher vem passando por transformações e ocupando espaços na economia, academia e sociedade de modo geral, o que vem acarretando o destaque da participação feminina em diversos contextos (Giuliano, 2014; Ramos, Aguas, \& Furtado, 2011).

Como reflexo de momentos históricos, a exemplo dos movimentos feministas da década de 1960, a mulher vem conquistando maior participação no espaço público (Baylão \& Schettino, 2014). No Brasil, de acordo com dados do Instituto Brasileiro de Geografia e Estatística [IBGE] (2008), observou-se o avanço da ocupação feminina no mercado de trabalho, onde, em 2007, a proporção de mulheres foi representada em $44 \%$ do total de trabalhadores.

A ascensão da representatividade feminina no meio científico brasileiro tornou-se evidente em 2010, quando, segundo o IBGE, o percentual de mulheres na universidade passou a representar $57,1 \%$ do total de universitários (Portal Brasil, 2016). Ainda, no período de 2009-2014, foi crescente a participação das mulheres no emprego total de mestres e doutores nas entidades empresariais, em que, em 2014, alcançaram, respectivamente, $48,0 \%$ e $52,3 \%$ do contingente, como apresenta o Centro de Gestão e Estudos Estratégicos [CGEE] (2016).

No que se refere à carreira contábil, algumas evidências históricas demonstram o progresso das mulheres nesta profissão. Isto pode ser observado em 2006, quando Maria Clara Cavalcante Bugarim tornou-se a primeira mulher Presidente do Conselho Federal de Contabilidade [CFC] (CFC, 2017).

Além disso, o incremento da representatividade feminina na contabilidade tornouse evidente devido ao aumento do contingente de mulheres estudantes de Ciências Contábeis, que, segundo o Exame Nacional de Desempenho de Estudantes [ENADE] (2012), passou a atingir $59 \%$ dos acadêmicos, bem como no que concerne à proporção de profissionais do gênero feminino, representados por $41 \%$ dos profissionais, conforme o CFC (2014). 
Análise da Produção Científica na Revista ABCustos: a participação feminina de 2006 a 2016 Clayton Robson Moreira da Silva, Laís Vieira Castro Oliveira, Cinthya Rachel Firmino de Morais, Diego

Sampaio Vasconcelos Ramalho Lima

Embora os dados direcionem a uma realidade em que homens e mulheres assumem posições equitativas, Lemos Júnior, Santini e Silveira (2015) argumentam que, em decorrência dos estereótipos de gênero, são observadas condições de desigualdade no que tange à remuneração, poder e prestígio social entre as mulheres na área contábil.

Nesta conjuntura, destaca-se a relevância do debate acerca dos reflexos da inserção da mulher na contabilidade como um meio de estimular a investigação das causas e implicações das desigualdades de gênero na sociedade. Desse modo, a percepção e atuação das mulheres no cenário contábil converteu-se em propósito de interesse social e levou ao desenvolvimento de diversos estudos (Silva Júnior \& Martins, 2017; Fernandes, Gomes, \& Ribeiro, 2016; Morais, Cabral, Santos, Pessoa, \& Oliveira, 2016; Coelho, 2015; Lemos Júnior et al., 2015; Silva et al., 2015; Soares, Lessa, Cabral, Pessoa, \& Santos, 2015; Vilela, 2015; Siqueira, Melz, Santos, \& Torres, 2013; Casa Nova, 2012; Resende, Ramos, Melo, Tomaz, Pacheco, \& Silva, 2012; De Luca, Gomes, Corrêa, \& Domingos, 2011; Pinheiro Neto, Mapurunga, \& Santos, 2010; Cruz, Marques, Silva, \& Cogan, 2010; Hukai \& Li, 2009; Cappelle, Brito, Melo, \& Vasconcelos, 2006).

Não obstante, ainda que os estudos que abordam gênero na contabilidade sejam reduzidos, tais pesquisas foram relevantes para que a problemática fosse introduzida no âmbito contábil na academia brasileira. Esses estudos contribuem à medida que levantam questionamentos e discussões acerca das desigualdades associadas às noções de gênero no que se refere à competência, empenho, prática e até mesmo ao ser contabilista, contribuindo para que se alcance a descontinuação do ciclo de perpetuação do desequilíbrio de poder e desigualdade de gênero na área (Silva et al., 2015).

Em meio às discussões acerca do papel da mulher na ciência, diversos estereótipos são endereçados ao gênero. A contabilidade, apesar de estar situada no campo das ciências sociais aplicadas, ainda busca se aproximar muito do paradigma positivista. Campos específicos da contabilidade utilizam a matemática como principal 
Análise da Produção Científica na Revista ABCustos: a participação feminina de 2006 a 2016 Clayton Robson Moreira da Silva, Laís Vieira Castro Oliveira, Cinthya Rachel Firmino de Morais, Diego

Sampaio Vasconcelos Ramalho Lima

instrumento de operacionalização, como o caso da contabilidade de custos. Nessa esteira, discute-se acerca da ausência de mulheres no campo das ciências exatas e de áreas que utilizam a matemática de forma mais acentuada, reforçando o estereótipo de que existem áreas masculinas e femininas (Cunha, Peres, Giordan, Bertoldo, Marques, \& Duncke, 2014).

Nessa seara, o mapeamento da participação de mulheres em áreas específicas das ciências contribui para o debate sobre gênero nessas áreas. Como mencionado, em campos específicos da contabilidade, como em finanças e custos, há forte utilização da matemática. Logo, faz-se relevante investigar como se caracteriza a participação feminina nessas áreas. Ainda que diversos estudos bibliométricos sobre custos tenham sido feitos (Nascimento, Bernardes, Sousa, Pinheiro, \& Castro, 2014; Carmo, Xavier, Pereira, \& Martins, 2014; Santos, 2015; Ribeiro \& Santos, 2016), não são observados estudos que destaquem a produção e participação feminina na área.

O presente estudo tem como foco as publicações feitas na Revista ABCustos, que é um dos poucos periódicos que aborda a temática custos como forma central. $A$ Revista $A B C u s t o s$ é uma publicação quadrimestral da Associação Brasileira de Custos, que teve a sua primeira edição publicada em 2006. Esse periódico tem como missão promover a divulgação da produção científica original, inédita e de qualidade na área de custos, sob uma abordagem multidisciplinar e no contexto da gestão das organizações, desenvolvida pelos pesquisadores, professores, alunos e profissionais do Brasil e de outros países, visando contribuir para a geração e o aprimoramento do conhecimento científico nessa área (ABCustos, 2017).

Nesse contexto, o presente estudo busca responder a seguinte questão de pesquisa: como se caracteriza a participação feminina na produção científica sobre custos na Revista ABCustos? Dessa forma, o objetivo do trabalho é analisar a participação feminina na produção científica sobre custos na Revista ABCustos. Adicionalmente, verificou-se o perfil dos artigos publicados no periódico.

O estudo justifica-se pela relevância das pesquisas que analisam a produção científica em uma determinada área de estudo, a fim de mapear e identificar diversos 
Análise da Produção Científica na Revista ABCustos: a participação feminina de 2006 a 2016 Clayton Robson Moreira da Silva, Laís Vieira Castro Oliveira, Cinthya Rachel Firmino de Morais, Diego

Sampaio Vasconcelos Ramalho Lima

aspectos inerentes ao campo. Ademais, verificar como se dá a participação feminina na área de custos, cujo crescimento é visível na área acadêmica, bem como analisar a produção científica em um dos periódicos específicos de custos, a revista ABCustos, apresenta relevância para os campos da contabilidade e da administração.

O trabalho está dividido em cinco seções, sendo a primeira esta introdução. A segunda seção conta com uma Revisão de Literatura, focando na participação feminina na produção científica e na produção científica sobre custos. A terceira seção aborda a metodologia delineada para o desenvolvimento desta pesquisa. A quarta seção traz a análise e a discussão dos resultados. Por fim, a quinta seção traz as considerações finais do estudo.

\section{REVISÃO DE LITERATURA}

\subsection{Participação Feminina na Produção Científica}

A inserção da mulher no ambiente acadêmico, assim como em outros âmbitos da sociedade, torna-se gradualmente mais representativa. Por conseguinte, as discussões acerca da representatividade, inclusão, percepção e atuação das mulheres no cenário contábil converteu-se em propósito de interesse social (Silva Júnior \& Martins, 2017; Fernandes et al., 2016; Morais et al. 2016; Coelho, 2015; Lemos Júnior et al., 2015; Silva et al., 2015; Soares et al., 2015; Vilela, 2015; Siqueira et al., 2013; Casa Nova, 2012; Resende et al., 2012; De Luca et al., 2011; Pinheiro Neto et al., 2010; Cruz et al., 2010; Hukai \& Li, 2009; Cappelle et al., 2006).

Contudo, ressalta-se que ainda não se sabe se o incremento de mulheres que atuam tanto no mercado de trabalho, quanto no âmbito acadêmico, está vinculado ao seu desempenho no campo científico contábil (De Luca et al., 2011).

Nesse sentido, embora haja um moderado contingente de pesquisas que discorram sobre o panorama da participação feminina no escopo científico, Santos (2010) argumenta que ainda há falta de mapeamento e conhecimento dessas produções. Além disso, compreender a disponibilização de informações desagregadas 
Análise da Produção Científica na Revista ABCustos: a participação feminina de 2006 a 2016

Clayton Robson Moreira da Silva, Laís Vieira Castro Oliveira, Cinthya Rachel Firmino de Morais, Diego

Sampaio Vasconcelos Ramalho Lima

por sexo se faz notório, uma vez que este aspecto tem sido fator determinante na política científica (Morais et al., 2016).

A partir da Figura 1, pode-se observar os objetivos, e principais resultados dos estudos sobre a participação feminina na produção científica.

\begin{tabular}{|c|c|c|}
\hline Autor(es) & Objetivo & Resultados \\
\hline $\begin{array}{l}\text { Fernandes et } \\
\text { al. (2016) }\end{array}$ & $\begin{array}{l}\text { Compreender a problemática do } \\
\text { acesso e do exercício na } \\
\text { profissão contabilística, na } \\
\text { perspectiva das mulheres que } \\
\text { desempenham a profissão. }\end{array}$ & $\begin{array}{l}\text { Segundo a opinião das entrevistadas, apesar da } \\
\text { maior facilidade no acesso à profissão, ainda } \\
\text { verificam-se desigualdades, discriminações e } \\
\text { sexíssimos que dificultam o exercício e a } \\
\text { progressão das mulheres na carreira. }\end{array}$ \\
\hline $\begin{array}{l}\text { Morais et al. } \\
\quad(2016)\end{array}$ & $\begin{array}{l}\text { Analisar como se caracteriza a } \\
\text { participação feminina na } \\
\text { produção científica nas revistas } \\
\text { brasileiras das áreas de } \\
\text { Administração e Ciências } \\
\text { Contábeis }\end{array}$ & $\begin{array}{l}\text { Verificou-se que a participação feminina é inferior } \\
\text { à masculina, representadas em } 38,04 \%, 35,93 \% \text { e } \\
38,06 \% \text { do total de autores, nos respectivos anos } \\
\text { de } 2013,2014 \text { e } 2015 \text {. Ainda, notou-se, que } \\
\text { quanto à natureza das pesquisas em que as } \\
\text { mulheres atuaram, a abordagem qualitativa foi a } \\
\text { mais utilizada por parte das pesquisadoras. }\end{array}$ \\
\hline Coelho (2015) & $\begin{array}{l}\text { Efetuar o mapeamento da } \\
\text { atuação da mulher doutora em } \\
\text { Contabilidade e aferir sua } \\
\text { contribuição acadêmica, por } \\
\text { meio de levantamento de sua } \\
\text { produção científica }\end{array}$ & $\begin{array}{l}\text { Verificou-se que as mulheres vêm conquistando } \\
\text { seu espaço no meio científico em Contabilidade e } \\
\text { contribuindo significativamente para o } \\
\text { desenvolvimento da Ciência Contábil. }\end{array}$ \\
\hline $\begin{array}{l}\text { Lemos Júnior } \\
\text { et al. (2015) }\end{array}$ & $\begin{array}{l}\text { Identificar e entender como os } \\
\text { processos de feminilização e } \\
\text { feminização na área contábil } \\
\text { são influenciados pelos } \\
\text { estereótipos de gênero, de } \\
\text { acordo com a perspectiva das } \\
\text { respondentes. }\end{array}$ & $\begin{array}{l}\text { Observou-se a existência de estereótipos, } \\
\text { permeando a compreensão de que as mulheres } \\
\text { têm uma melhor preparação para as atividades } \\
\text { operacionais da área, por serem mais detalhistas } \\
\text { e dóceis do que o homem. Ainda, embora haja um } \\
\text { crescente número de mulheres na profissão, a } \\
\text { desigualdade institucionalizada é mantida na } \\
\text { Contabilidade. }\end{array}$ \\
\hline $\begin{array}{l}\text { Silva et al. } \\
\text { (2015) }\end{array}$ & $\begin{array}{l}\text { Investigar } 0 \text { perfil das } \\
\text { publicações em periódicos } \\
\text { brasileiros sobre gênero no } \\
\text { campo da contabilidade, em } \\
\text { particular, aquelas em que as } \\
\text { questões de gênero } \\
\text { compreendem o contexto das } \\
\text { mulheres estudadas. }\end{array}$ & $\begin{array}{l}\text { Os resultados demonstram que há poucas } \\
\text { publicações sobre gênero na área contábil, } \\
\text { concentradas entre os anos de } 2011 \text { e } 2012 \text { e que } \\
\text { as mulheres representam } 67 \% \text { das autorias. }\end{array}$ \\
\hline $\begin{array}{l}\text { Soares et al. } \\
\quad(2015)\end{array}$ & $\begin{array}{l}\text { Analisar a participação feminina } \\
\text { na produção científica sobre } \\
\text { Estratégia. }\end{array}$ & $\begin{array}{l}\text { Observou-se que, dentre os } 227 \text { artigos } \\
\text { analisados, apenas } 42 \text { apresentavam autoria } \\
\text { exclusivamente feminina. Finalmente, verificou-se } \\
\text { que, embora haja uma baixa representatividade de } \\
\text { mulheres nos estudos sobre estratégia, notou-se } \\
\text { um progresso da participação feminina no decorrer } \\
\text { do período estudado. }\end{array}$ \\
\hline Vilela (2015) & Conhecer e compreender & Constatou-se que o número de mulheres passou a \\
\hline
\end{tabular}


Análise da Produção Científica na Revista ABCustos: a participação feminina de 2006 a 2016

Clayton Robson Moreira da Silva, Laís Vieira Castro Oliveira, Cinthya Rachel Firmino de Morais, Diego

Sampaio Vasconcelos Ramalho Lima

\begin{tabular}{|c|c|c|}
\hline & $\begin{array}{l}\text { acesso das mulheres ao estudo } \\
\text { da Contabilidade em Portugal }\end{array}$ & $\begin{array}{l}\text { se aproximar ao percentual masculino na década } \\
\text { de 1940, chegando a } 43 \% \text { do contingente e, } \\
\text { apesar das dificuldades enfrentadas devido à fase } \\
\text { de conflito interno vivido por este país na década } \\
\text { de } 1970 \text {, o número de mulheres aumentou mais } \\
\text { em comparação aos homens. A pesquisa ainda } \\
\text { ressalta que as mulheres foram vítimas de } \\
\text { discriminação e desigualdade de gênero no âmbito } \\
\text { educacional. }\end{array}$ \\
\hline $\begin{array}{l}\text { Siqueira et al. } \\
\qquad(2013)\end{array}$ & $\begin{array}{l}\text { Avaliar, pelo meio de } \\
\text { entrevistas, a inserção da } \\
\text { mulher como profissional } \\
\text { contábil nos escritórios de } \\
\text { contabilidade da cidade de } \\
\text { Tangará da Serra- MT. }\end{array}$ & $\begin{array}{l}\text { Segundo as entrevistadas, embora os clientes e } \\
\text { patrões não lhes confiram credibilidade, este fato } \\
\text { faz com que as profissionais de contabilidade } \\
\text { busquem um maior aprimoramento para uma boa } \\
\text { desenvoltura profissional. }\end{array}$ \\
\hline $\begin{array}{l}\text { Casa Nova } \\
\quad(2012)\end{array}$ & $\begin{array}{l}\text { Examinar a trajetória dos } \\
\text { egressos dos programas } \\
\text { especiais de Pós-Graduação em } \\
\text { Controladoria e Contabilidade } \\
\text { da FEA/USP, analisando o } \\
\text { impacto que o programa possa } \\
\text { ter tido em sua evolução e } \\
\text { avaliando especialmente os } \\
\text { possíveis efeitos que o desenho } \\
\text { distinto dos programas possa ter } \\
\text { tido em termos da participação e } \\
\text { permanência de mulheres. }\end{array}$ & $\begin{array}{l}\text { A partir dos resultados pode se observar o } \\
\text { programa especial de Mestrado em Contabilidade } \\
\text { do CFC, em formato semi-presencial, permitiu } \\
\text { uma maior participação das mulheres, tendo em } \\
\text { vista a possibilidade de maior conciliação com a } \\
\text { vida familiar e pessoal. }\end{array}$ \\
\hline $\begin{array}{l}\text { Resende et al. } \\
\text { (2012) }\end{array}$ & $\begin{array}{l}\text { Investigar a participação } \\
\text { feminina na produção científica } \\
\text { da divisão de finanças publicada } \\
\text { nos EnANPADs de } 2000 \text { a } 2010\end{array}$ & $\begin{array}{l}\text { Dentre o total de artigos analisados, } 27 \text { são de } \\
\text { autoria exclusivamente feminina e } 184 \text { de autoria } \\
\text { mista (feminino e masculino), o que fez os } \\
\text { pesquisadores constatarem a supremacia } \\
\text { masculina na produção científica destes eventos. } \\
\text { Ainda, observou-se maior preferência feminina } \\
\text { pela subárea de finanças corporativas e, a } \\
\text { masculina, de mercados financeiros e de capitais. }\end{array}$ \\
\hline $\begin{array}{l}\text { De Luca et al. } \\
\text { (2011) }\end{array}$ & $\begin{array}{l}\text { Analisar a participação feminina } \\
\text { na produção científi- ca em } \\
\text { contabilidade publicada nos } \\
\text { anais dos Encontros da } \\
\text { Associação Nacional de Pós- } \\
\text { graduação e Pesquisa em } \\
\text { Administração [EnANPAD], dos } \\
\text { Congressos USP de } \\
\text { Controladoria e Contabilidade e } \\
\text { da Associação Nacional } \\
\text { dos Programas de Pós- } \\
\text { graduação em Ciências } \\
\text { Contábeis [ANPCONT]. }\end{array}$ & $\begin{array}{l}\text { Os achados desta pesquisa mostraram que dentre } \\
\text { os } 755 \text { artigos estudados, (58,35\%) detém } \\
\text { participação feminina. Além disso, observou-se } \\
\text { que a região sudeste possui quase que metade } \\
\text { deste contingente totalizados em } 45,5 \% \text {, ao } \\
\text { mesmo tempo que se notou um avanço } \\
\text { significativo da quantidade de mulheres nos } \\
\text { artigos publicados no EnANPAD entre } 2004 \text { e } \\
2007 \text {, havendo, entretanto, um decréscimo dessa } \\
\text { participação no período de } 2007 \text { a } 2009 \text {. }\end{array}$ \\
\hline $\begin{array}{l}\text { Cruz et al. } \\
(2010)\end{array}$ & $\begin{array}{l}\text { Analisar os trabalhos científicos } \\
\text { com abordagem no tema } \\
\text { "Teoria das "Restrições" (TOC), } \\
\text { apresentados no Congresso }\end{array}$ & $\begin{array}{l}\text { Dentre a análises sobre a autoria dos artigos nesta } \\
\text { temática, observou-se que quanto ao gênero os } \\
\text { dados apontaram o predomínio de autores do } \\
\text { sexo masculino, representados por } 74,3 \% \text {, }\end{array}$ \\
\hline
\end{tabular}


Análise da Produção Científica na Revista ABCustos: a participação feminina de 2006 a 2016 Clayton Robson Moreira da Silva, Laís Vieira Castro Oliveira, Cinthya Rachel Firmino de Morais, Diego

Sampaio Vasconcelos Ramalho Lima

\begin{tabular}{|l|l|l|}
\hline & $\begin{array}{l}\text { Brasileiro de Custos (CBC) de } \\
1994 \text { a 2008, por meio de um } \\
\text { estudo bibliométrico. }\end{array}$ & $\begin{array}{l}\text { enquanto que o gênero feminino concentra 25,7\% } \\
\text { do total de autores. }\end{array}$ \\
\hline
\end{tabular}

Figura 1. Pesquisas publicadas sobre a participação feminina na produção científica Nota. Fonte: Elaborado pelos autores.

As pesquisas apresentadas na Figura 1 contemplam aspectos relacionados à produção científica feminina, como: (i) a proporção de mulheres nas autorias; (ii) as temáticas abordadas; (iii) a natureza de pesquisas mais evidenciadas pelas autoras; e (iv) a percepção da mulher no ambiente profissional-acadêmico.

Todavia, nota-se uma lacuna de estudos que desenvolvem o mapeamento da participação feminina na produção científica no campo da contabilidade. Essa lacuna é ainda mais acentuada quando se delimita um tema mais específico nessa área, como as pesquisas sobre custos. Dessa forma, a percepção da inclusão feminina na esfera acadêmica apresenta-se relevante e proporciona meios de se compreender a evolução e inserção das mulheres neste ambiente.

\subsection{Produção Científica sobre Custos}

A Contabilidade de Custos é a área das Ciências Contábeis que produz dados e informações para os diversos níveis gerenciais, vindo a confirmar sua utilização como mecanismo de gestão e controle da organização (Hofer, Pacheco, Souza, \& Protil 2011). Segundo Megliorini (2012), conhecer custos é uma condição essencial para gerir uma empresa, independentemente do tipo e do porte.

Nesse sentido, Crepaldi (2010) traz a definição de Contabilidade de Custos como sendo uma técnica utilizada para identificar, mensurar e informar os custos dos produtos e serviços. Ela tem a função de gerar informações precisas e rápidas para a administração, para a tomada de decisões. É voltada para a análise de gastos da entidade no decorrer de suas operações.

As informações advindas dos custos são relevantes e necessárias para o processo de tomada de decisões de uma organização, pois uma tomada de decisão equivocada pode afetar o seu equilíbrio e, o gestor, que está imerso em um cenário 
Análise da Produção Científica na Revista ABCustos: a participação feminina de 2006 a 2016

Clayton Robson Moreira da Silva, Laís Vieira Castro Oliveira, Cinthya Rachel Firmino de Morais, Diego

Sampaio Vasconcelos Ramalho Lima

empresarial repleto de incertezas e mudanças, precisa de informações conexas, tempestivas e transparentes a respeito dos custos (Scharf, Borgert, \& Richartz, 2011; Ribeiro \& Santos, 2016).

Dessa maneira, analisar a produção científica em determinada área de conhecimento faz-se necessário, a fim de conhecer o que se tem abordado nos artigos publicados. A produção científica contábil possibilita apresentar pesquisas válidas que podem ser divulgadas às pessoas que buscam o conhecimento. (Ferrari, Camacho, Rodrigues, Marroni, \& Panosso, 2012; Cunha \& Kremer, 2013).

Algumas pesquisas foram realizadas na área de custos e no seu amplo campo de conhecimento. A Figura 2 apresenta algumas pesquisas relacionadas à produção científica sobre custos nessa última década. São apresentados os objetivos dos estudos, bem como os principais resultados.

\begin{tabular}{|c|c|c|}
\hline Autor (es) & Objetivo & $\begin{array}{c}\text { Resultados } \\
\end{array}$ \\
\hline $\begin{array}{c}\text { Ribeiro \& } \\
\text { Santos } \\
(2016)\end{array}$ & $\begin{array}{l}\text { Investigar o estado da arte da } \\
\text { produção acadêmica do tema custos } \\
\text { divulgada nos periódicos nacionais } \\
\text { da área contábil de } 2010 \text { a } 2014 \text {. }\end{array}$ & $\begin{array}{l}\text { Os principais resultados foram: (a) o periódico } \\
\text { Custos e @gronegócio Online ficou em realce } \\
\text { neste estudo; (b) Marcos Antonio de Souza foi } \\
\text { o autor mais profícuo; (c) a Universidade } \\
\text { Federal de Santa Catarina (UFSC) se } \\
\text { destacou na produção acadêmica do tema } \\
\text { investigado. Nas redes sociais investigadas, } \\
\text { observou-se baixa densidade e alta } \\
\text { centralidade de grau nas redes analisadas, } \\
\text { sendo que grande parte dos atores que } \\
\text { ficaram em ênfase no degree também ficaram } \\
\text { em evidência na centralidade de } \\
\text { intermediação. Os temas abordados que } \\
\text { ficaram em realce neste estudo foram: gestão } \\
\text { de custos e custeio ABC. }\end{array}$ \\
\hline $\begin{array}{l}\text { Santos } \\
\text { (2015) }\end{array}$ & $\begin{array}{l}\text { Apresentar uma análise dos artigos } \\
\text { publicados como estudos } \\
\text { bibliométricos no Congresso } \\
\text { Brasileiro de Custos (CBC). }\end{array}$ & $\begin{array}{l}\text { A instituição de ensino mais prolixa foi a } \\
\text { Universidade Federal de Santa Catarina, com } \\
25 \text { autores vinculados, seguida pela } \\
\text { Universidade Federal de Uberlândia (20) e } \\
\text { Universidade do Estado de São Paulo (18) e o } \\
\text { trecho Sul-Sudeste é o que mais publica. O } \\
\text { trabalho evidenciou que, nos } 55 \text { artigos } \\
\text { analisados, foram utilizadas } 1.449 \text { referências } \\
\text { bibliográficas. O artigo com menor número de } \\
\text { referências bibliográficas utilizou } 9 \text {, enquanto o } \\
\text { artigo com maior número de referências } \\
\text { utilizou } 65 \text {. O número médio de referências } \\
\text { bibliográficas por artigo foi de } 26 \text {. As }\end{array}$ \\
\hline
\end{tabular}


Análise da Produção Científica na Revista ABCustos: a participação feminina de 2006 a 2016

Clayton Robson Moreira da Silva, Laís Vieira Castro Oliveira, Cinthya Rachel Firmino de Morais, Diego

Sampaio Vasconcelos Ramalho Lima

\begin{tabular}{|c|c|c|}
\hline & & $\begin{array}{l}\text { referências nacionais são as mais usuais: } 72 \% \\
\text { contra } 28 \% \text { das internacionais. E as fontes de } \\
\text { pesquisas mais usadas são as revistas, com } \\
585 \text { referências, seguidas dos livros com } 457 \text {. }\end{array}$ \\
\hline $\begin{array}{l}\text { Carmo et al. } \\
\text { (2014) }\end{array}$ & $\begin{array}{l}\text { Compreender o perfil das pesquisas } \\
\text { elaboradas pelos alunos do } \\
\text { programa de pós-graduação stricto } \\
\text { sensu em Contabilidade da } \\
\text { Faculdade de Economia, } \\
\text { Administração e Contabilidade da } \\
\text { Universidade de São Paulo, entre os } \\
\text { anos } 1998 \text { e } 2011 \text {, com ênfase nas } \\
\text { áreas de Contabilidade Gerencial e } \\
\text { de Contabilidade de Custos. }\end{array}$ & $\begin{array}{l}\text { As pesquisas relacionadas à "gestão de } \\
\text { custos" e "custos dos concorrentes" tiveram } \\
\text { maior representatividade dentre os temas } \\
\text { pesquisados. }\end{array}$ \\
\hline $\begin{array}{l}\text { Nascimento } \\
\text { et al. (2014) }\end{array}$ & $\begin{array}{l}\text { Realizar um estudo bibliométrico nas } \\
19 \text { edições do Congresso Brasileiro } \\
\text { de Custos (CBC), onde foram } \\
\text { selecionados } 44 \text { artigos publicados } \\
\text { com os temas Custeio-Alvo, Custeio- } \\
\text { Meta e "Target Costing". }\end{array}$ & $\begin{array}{l}\text { Wellington Rocha ocupa a posição central da } \\
\text { rede de pesquisadores de Custeio-Alvo no } \\
\text { CBC, sendo o autor mais influente e com } \\
\text { maior prestígio no contexto analisado. Por fim, } \\
\text { observaram ainda que os livros continuam a } \\
\text { ser a principal fonte de referências. }\end{array}$ \\
\hline $\begin{array}{l}\text { Moraes } \\
\text { Júnior, } \\
\text { Araújo \& } \\
\text { Rezende } \\
\text { (2013) }\end{array}$ & $\begin{array}{l}\text { Fazer um levantamento, no período } \\
\text { de } 2007 \text { a } 2009 \text {, da área "ensino e } \\
\text { pesquisa na gestão de custos", } \\
\text { integrante do CBC. }\end{array}$ & $\begin{array}{l}\text { A região com } 40 \% \text { de trabalhos aprovados é a } \\
\text { Sudeste, sendo que no triênio analisado, a } \\
\text { FURB teve oito artigos selecionados entre as } \\
36 \text { Instituições de Ensino Superior [IES] que } \\
\text { aprovaram textos na área temática estudada. }\end{array}$ \\
\hline $\begin{array}{l}\text { Reis, Cruz, } \\
\quad \text { Rocha \& } \\
\text { Souza (2012) }\end{array}$ & $\begin{array}{l}\text { Analisar as publicações voltadas } \\
\text { para a abordagem de gestão de } \\
\text { custos no Encontro Anual da } \\
\text { Associação Nacional de Pós- } \\
\text { Graduação e Pesquisa em } \\
\text { Administração [EnANPAD] de } 1997 \text { a } \\
2008 \text {. }\end{array}$ & $\begin{array}{l}\text { Em relação ao mapeamento dos elos } \\
\text { relacionais entre os autores, pode-se perceber } \\
\text { uma baixa densidade geral, sendo igual a } \\
0,0183 \text { no período de } 1997-2002 \text { e a } 0,0115 \\
\text { no período de } 2003-2008 \text {, cercada por baixa } \\
\text { média de centralidade, evidenciando suposta } \\
\text { relação embrionária no desenvolvimento das } \\
\text { cooperações entre pesquisadores das } \\
\text { temáticas de Gestão de Custos no EnANPAD } \\
\text { nos últimos } 12 \text { anos. }\end{array}$ \\
\hline $\begin{array}{l}\text { Machado, } \\
\text { Silva, \& } \\
\text { Beuren } \\
(2012)\end{array}$ & $\begin{array}{l}\text { Identificar as características da } \\
\text { produção científica de custos } \\
\text { publicados em periódicos nacionais } \\
\text { de contabilidade listados no } \\
\text { Qualis/CAPES, sob a perspectiva } \\
\text { das redes sociais e da bibliometria. }\end{array}$ & $\begin{array}{l}\text { As temáticas em custos abordam: métodos de } \\
\text { custeio, com } 23 \text { artigos; custos para } \\
\text { planejamento e controle, com } 20 \text { artigos; } \\
\text { aplicações em custos, com } 19 \text { artigos; } \\
\text { abordagem contemporânea, com } 15 \text { artigos; e } \\
\text { a temática de ensino e pesquisa, com } 5 \\
\text { artigos. }\end{array}$ \\
\hline $\begin{array}{l}\text { Oliveira \& } \\
\text { Aragão } \\
\text { (2011) }\end{array}$ & $\begin{array}{l}\text { Conhecer as características dos } \\
\text { artigos sobre custos publicados em } \\
\text { revistas brasileiras online com } \\
\text { avaliação Qualis-Capes A1, A2, B1 e } \\
\text { B2. }\end{array}$ & 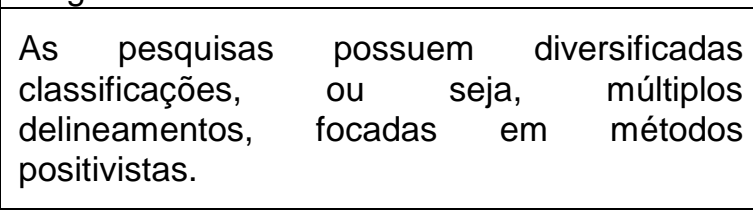 \\
\hline $\begin{array}{l}\text { Walter } \\
(2010)\end{array}$ & $\begin{array}{l}\text { Traçar um perfil dos artigos } \\
\text { publicados no periódico Custos e } \\
\text { @gronegócio Online. }\end{array}$ & $\begin{array}{l}\text { O tema acadêmico mais abordado é o de } \\
\text { custos de produção, e a área do agronegócio } \\
\text { mais discutida é aquela relacionada ao leite } \\
\text { (cadeia produtiva, pecuária e produção leiteira, } \\
\text { e fabricação de laticínios). }\end{array}$ \\
\hline
\end{tabular}


Análise da Produção Científica na Revista ABCustos: a participação feminina de 2006 a 2016 Clayton Robson Moreira da Silva, Laís Vieira Castro Oliveira, Cinthya Rachel Firmino de Morais, Diego

Sampaio Vasconcelos Ramalho Lima

\begin{tabular}{|c|c|c|}
\hline $\begin{array}{l}\text { Rocha, } \\
\text { Wienhage, \& } \\
\text { Scarpin } \\
(2010)\end{array}$ & $\begin{array}{l}\text { Investigar a produção científica por } \\
\text { meio de um estudo bibliométrico } \\
\text { sobre Custeio-Meta e Custeio- } \\
\text { Kaizen. }\end{array}$ & $\begin{array}{l}\text { O tema custeio-alvo foi o mais abordado pelos } \\
\text { artigos. Não há a existência de laços fortes } \\
\text { entre os autores. }\end{array}$ \\
\hline
\end{tabular}

Figura 2. Pesquisas publicadas sobre a produção acadêmica em custos

Nota. Fonte: Elaborado pelos autores.

Os estudos contemplados na Figura 2 apresentam, de maneira abrangente, a relevância do tema custos em vários aspectos, destacando características que se fazem necessárias para um melhor entendimento e compreensão do tema em estudo, sendo muito relevante e essencial para as Ciências Contábeis, pois norteia e promove um maior controle na gestão das organizações.

Porém, ao se verificar os estudos delineados na Figura 2, nota-se que os mesmos não evidenciam dados e informações tão recentes, bem como não abordam a questão da participação feminina na produção científica em custos. Nesse contexto, o atual estudo vem para tentar mitigar tais ausências, contribuindo para uma expansão e robustez do tema custos na literatura acadêmica nacional focada em um periódico especializado na área, fomentando assim o campo do conhecimento da Contabilidade, sobretudo no que se refere aos custos e aos respectivos assuntos que o cercam.

\section{METODOLOGIA}

O estudo classifica-se como quantitativo e qualitativo. Ressalta-se que a pesquisa quantitativa é caracterizada pelo uso de técnicas estatísticas das mais simples, como percentual, frequências, média, desvio padrão, às mais complexas, enquanto a pesquisa qualitativa foca a interpretação e compreensão de dados não numéricos (Richardson, 2008; Collis, \& Hussey, 2005). Destarte, coadunar essas abordagens proporciona maior robustez nas análises e compreensão do fenômeno estudado. No que tange ao objetivo, trata-se de um estudo descritivo. De acordo com Gray (2012), pesquisa descritiva é aquela que busca descrever uma situação, pessoa ou evento, ou apontar como os objetos descritos estão relacionados entre si. 
Análise da Produção Científica na Revista ABCustos: a participação feminina de 2006 a 2016 Clayton Robson Moreira da Silva, Laís Vieira Castro Oliveira, Cinthya Rachel Firmino de Morais, Diego

Sampaio Vasconcelos Ramalho Lima

A pesquisa foi conduzida por meio de um estudo bibliométrico, que tem como finalidade a análise das características quantitativas da produção, disseminação e utilização da informação publicada (Michels \& Schmoch, 2014; Pinto, Efrain-García, Barquín, \& González, 2007; Macias-Chapula, 1998). Utilizou-se a técnica de análise de conteúdo para o tratamento dos dados (Bardin, 2009).

O universo de investigação contemplou todos os artigos publicados na Revista ABCustos, no período de 2006 a 2016. Os artigos foram coletados do website do periódico e totalizam 173 artigos.

A análise da participação feminina foi realizada em quatro etapas: (i) diferenciação dos artigos por gênero dos autores, evidenciando o número de artigos que possuem apenas mulheres na autoria, apenas homens e homens e mulheres; (ii) quantidade de participações de homens e mulheres que publicaram no periódico; (iii) quantidade de autores e autores por região; e (iv) evidenciação dos autores que mais publicaram no periódico, dando destaque às mulheres que mais publicaram.

Em relação ao perfil dos artigos publicados, foram analisados os seguintes aspectos: (i) número de autores por artigo; (ii) quanto à abordagem utilizada; e (iii) as temáticas mais utilizadas nos artigos. Além disso, foram verificadas as IES que mais publicaram na Revista ABCustos.

Para análise do perfil dos autores, foram pesquisados os currículos dos autores identificados nos 173 artigos analisados. O gênero dos autores foi identificado com base no nome e/ou nas fotografias presentes em seus currículos. Considerou-se como região, aquela que era apresentada no campo "endereço profissional" no currículo dos autores. A titulação considerada foi a mais elevada com status de concluída; e o vínculo institucional foi considerado de acordo com a seguinte ordem de prioridades: (i) se docente da IES; (ii) se estudante de programa de pós-graduação; (iii) IES em que obteve a última titulação, quando não docente ou discente. Foram excluídos das análises de perfil aqueles autores que não apresentaram currículo na Plataforma Lattes.

Ao fim, foi elaborado uma lista contendo os autores que mais publicaram na Revista ABCustos. Com base nessa lista, foram destacadas as mulheres que mais 
Análise da Produção Científica na Revista ABCustos: a participação feminina de 2006 a 2016

Clayton Robson Moreira da Silva, Laís Vieira Castro Oliveira, Cinthya Rachel Firmino de Morais, Diego

Sampaio Vasconcelos Ramalho Lima

publicaram, com a finalidade de se discutir acerca do perfil das mulheres que mais publicaram no periódico.

\section{ANÁLISE E DISCUSSÃO DOS RESULTADOS}

Esta seção destina-se à análise dos resultados obtidos nesta pesquisa, que teve como objetivo analisar a participação feminina na produção científica sobre custos mediante a análise dos artigos publicados na Revista ABCustos. Adicionalmente, verificou-se o perfil dos artigos publicados no periódico. Dessa forma, as tabelas e demais recursos a seguir servirão como arcabouço para o desenvolvimento desta seção.

Dessa maneira, a Tabela 1 traz o panorama geral sobre o número de artigos publicados na Revista ABCustos, desde seu primeiro ano. Foram divididos os artigos em: (i) artigos apenas com mulheres na autoria; (ii) artigos apenas com homens na autoria; e (iii) artigos mistos, ou seja, com homens e mulheres na autoria.

Tabela 1

Distribuição dos artigos da $A B C u s t o s$ em relação ao gênero dos autores

\begin{tabular}{|c|c|c|c|c|c|c|c|c|c|c|c|c|}
\hline Artigos Publicados / Ano & ๕ి & ণ্ণ & ঃ̊ & 옹 & 웅 & స్ & ํㅗํ & ำ & $\underset{\text { స్ }}{+}$ & $\frac{10}{\infty}$ & $\stackrel{0}{\text { N }}$ & $\begin{array}{l}\bar{\pi} \\
\text { ర0 }\end{array}$ \\
\hline Artigos apenas com mulheres & - & 2 & 2 & 1 & 3 & - & 1 & 3 & - & - & 1 & 13 \\
\hline Artigos apenas com homens & 4 & 7 & 6 & 7 & 5 & 7 & 5 & 4 & 3 & 4 & 3 & 55 \\
\hline Artigos com homens e mulheres & 2 & 9 & 10 & 10 & 10 & 10 & 10 & 10 & 12 & 11 & 11 & 105 \\
\hline Total & 6 & 18 & 18 & 18 & 18 & 17 & 16 & 17 & 15 & 15 & 15 & 173 \\
\hline
\end{tabular}

Nota. Fonte: Dados da pesquisa.

Com base na distribuição dos artigos por ano, observou-se que, nos anos de 2008 a 2010, o periódico publicou um número maior de artigos (18) e, a partir de 2014, passou a publicar um número menor (15) por ano. Ressalta-se que a revista tem publicações quadrimestrais, sendo divulgados 3 números por ano. O baixo número de 
Análise da Produção Científica na Revista ABCustos: a participação feminina de 2006 a 2016 Clayton Robson Moreira da Silva, Laís Vieira Castro Oliveira, Cinthya Rachel Firmino de Morais, Diego

Sampaio Vasconcelos Ramalho Lima

artigos no ano de 2006 deve-se ao fato de o periódico ter publicado apenas um número em seu primeiro ano de funcionamento.

No que tange ao gênero dos autores que publicam no periódico, as informações contidas na Tabela 1 sugerem que o número de artigos apenas com mulheres na autoria (13) é inferior ao número de artigos produzidos apenas por homens (55), corroborando os achados de Resende et al. (2012), De Luca et al. (2011) e Cruz et al. (2010), que analisaram a participação de autores quanto a seu gênero em produções sobre temas específicos nas áreas de administração e contabilidade.

Ainda em relação ao gênero dos autores, Resende et al. (2012) verificaram que o número de artigos apenas com homens é superior ao número de artigos de autoria mista na área de finanças, diferentemente deste estudo que, de acordo com a Tabela 1, é possível observar que o número de artigos de autoria mista (105) é superior ao número de artigos apenas com homens (55). Porém, ainda observa-se acentuada diferença entre o total de artigos apenas com mulheres (13) e os demais arranjos (masculinos e mistos). Este resultado assemelha-se ao de De Luca et al. (2011), que também observaram um número de artigos mistos superior ao de artigos masculinos, mas um baixo número de artigos apenas de mulheres.

No que tange à quantidade de autores que compõem os artigos, a Tabela 2 traz uma visão geral acerca do número de indivíduos por artigo. A Revista ABCustos, em seu website, na aba "diretrizes para autores", estipula que a quantidade máxima de autores por artigo é de 5 autores, entretanto, foram observados 2 artigos com 6 autores, um no ano de 2010 e outro no ano de 2011. 
Análise da Produção Científica na Revista ABCustos: a participação feminina de 2006 a 2016

Clayton Robson Moreira da Silva, Laís Vieira Castro Oliveira, Cinthya Rachel Firmino de Morais, Diego

Sampaio Vasconcelos Ramalho Lima

Tabela 2

Distribuição dos artigos por número de autores

\begin{tabular}{|c|c|c|c|c|c|c|c|c|c|c|c|c|}
\hline № de Autores / Ano & ষ্ণ & 옹 & \&્స & ষ্ণ & 웅 & స్ & Nㅜㅇ & ำ & $\underset{\text { స }}{+}$ & $\frac{10}{\infty}$ & $\frac{0}{\tilde{N}}$ & $\begin{array}{l}\bar{\pi} \\
\text { 0 }\end{array}$ \\
\hline 1 autor (a) & 1 & 3 & - & - & 3 & 1 & - & - & - & 1 & - & 9 \\
\hline 2 autores (as) & 3 & 4 & 3 & 4 & 3 & 4 & 2 & 4 & 3 & 2 & 1 & 33 \\
\hline 3 autores (as) & 1 & 9 & 9 & 10 & 4 & 5 & 8 & 5 & 5 & 3 & 4 & 63 \\
\hline 4 autores (as) & - & 2 & 5 & 2 & 6 & 5 & 5 & 6 & 4 & 4 & 2 & 41 \\
\hline 5 autores (as) & 1 & - & 1 & 2 & 1 & 1 & 1 & 2 & 3 & 5 & 8 & 25 \\
\hline 6 autores (as) & - & - & - & - & 1 & 1 & - & - & - & - & - & 2 \\
\hline Total & 6 & 18 & 18 & 18 & 18 & 17 & 16 & 17 & 15 & 15 & 15 & 173 \\
\hline
\end{tabular}

Nota. Fonte: Dados da pesquisa.

Ainda sobre a quantidade de autores por artigo, observou-se que os trios são mais frequentes, estando esse arranjo presente em 63 artigos, o que corrobora o estudo de Walter (2010), que analisou os artigos publicados em um outro periódico específico da área de custos. Oliveira e Aragão (2011) obtiveram resultados semelhantes em seu estudo sobre a produção científica sobre custos, tendo observado que os arranjos mais comuns são duplas e trios, com 20 artigos sobre o tema cada, de um total de 59 que analisaram.

Os resultados encontrados por Machado et al. (2012) divergem dos achados do presente estudo, visto que os autores verificaram que as duplas são mais recorrentes nos estudos sobre custos em periódicos de contabilidade. Além disso, Barboza et al. (2015) verificaram que o arranjo mais comum nos artigos bibliométricos publicados no Congresso Brasileiro de Custos é de 4 autores por artigo.

No que tange ao número de autores por gênero, a Tabela 3 apresenta a distribuição deles no decorrer dos anos. Primeiramente, foi observada a quantidade de autoras com participação nos artigos. Posteriormente, observou-se o número de autores que publicaram na Revista ABCustos. 
Análise da Produção Científica na Revista ABCustos: a participação feminina de 2006 a 2016 Clayton Robson Moreira da Silva, Laís Vieira Castro Oliveira, Cinthya Rachel Firmino de Morais, Diego

Tabela 3

Quantidade de autores por gênero

\begin{tabular}{|c|c|c|c|c|c|c|c|c|c|c|c|c|}
\hline $\begin{array}{l}\text { Quantidade de } \\
\text { Autores por } \\
\text { gênero }\end{array}$ & ஜ̊ํ & ్ㅗㅇ & : & 옹 & 옹 & Г్ర & 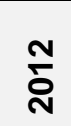 & $\frac{m}{\text { N }}$ & $\stackrel{+}{\sim}$ & $\frac{10}{\text { న }}$ & $\stackrel{\circ}{\circ}$ & $\begin{array}{l}\bar{\pi} \\
\text { 0 }\end{array}$ \\
\hline Autoras (M) & 2 & 15 & 25 & 20 & 20 & 14 & 15 & 25 & 19 & 19 & 29 & 203 \\
\hline Autores $(\mathrm{H})$ & 13 & 31 & 33 & 36 & 36 & 41 & 37 & 29 & 30 & 36 & 33 & 355 \\
\hline Total (M e H) & 15 & 46 & 58 & 56 & 56 & 55 & 52 & 54 & 49 & 55 & 62 & 558 \\
\hline
\end{tabular}

Nota. Fonte: Dados da pesquisa.

Com base na Tabela 3, observa-se que o número de mulheres que publicam no periódico é inferior ao número de homens. Esse resultado alinha-se aos resultados obtidos por Soares et al. (2014) e Cruz et al. (2010), que constataram que a participação feminina em produções científicas nas áreas de administração e contabilidade é inferior à participação do gênero oposto. Em relação a isso, De Luca et al. (2011) advogam que a participação feminina na produção científica da área de contabilidade ainda é inferior em relação à participação masculina, mesmo com o avanço das mulheres na participação no mercado de trabalho e na luta por direitos iguais.

Ainda sobre o gênero dos indivíduos que publicaram na Revista ABCustos, a Tabela 4 traz a distribuição dos autores por região. Foram observados o número de autores homens e mulheres de acordo com suas origens institucionais e acadêmicas. 
Análise da Produção Científica na Revista ABCustos: a participação feminina de 2006 a 2016 Clayton Robson Moreira da Silva, Laís Vieira Castro Oliveira, Cinthya Rachel Firmino de Morais, Diego

Tabela 4

Quantidade de autores por gênero distribuídos pelas regiões brasileiras

\begin{tabular}{|c|c|c|c|c|c|c|c|c|c|c|c|c|c|c|c|c|}
\hline \multirow{2}{*}{$\begin{array}{c}\text { Regiã } \\
\mathbf{0}\end{array}$} & \multicolumn{2}{|c|}{$\begin{array}{l}\stackrel{0}{ \pm} \\
\mathbf{z}\end{array}$} & \multicolumn{2}{|c|}{$\begin{array}{l}\frac{0}{0} \\
\text { d } \\
\text { 힌 } \\
\text { z }\end{array}$} & \multicolumn{2}{|c|}{ 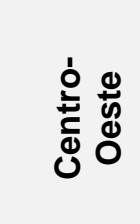 } & \multicolumn{2}{|c|}{ 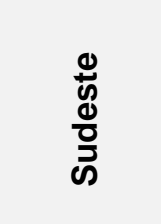 } & \multicolumn{2}{|c|}{$\overline{\bar{̉}}$} & \multicolumn{2}{|c|}{ 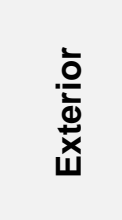 } & \multicolumn{2}{|c|}{ 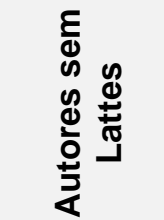 } & \multicolumn{2}{|c|}{$\begin{array}{l}\bar{\pi} \\
\text { 0 } \\
\text { - }\end{array}$} \\
\hline & M & $\mathrm{H}$ & M & H & M & $\mathrm{H}$ & M & $\mathrm{H}$ & M & H & M & $\mathrm{H}$ & $\mathbf{M}$ & $\mathbf{H}$ & M & $\mathrm{H}$ \\
\hline 2006 & - & - & - & 2 & 1 & - & - & 4 & 1 & 7 & - & - & - & - & 2 & 13 \\
\hline 2007 & - & - & 3 & 5 & - & - & 3 & 11 & 8 & 14 & - & - & 1 & 1 & 15 & 31 \\
\hline 2008 & - & - & 7 & 4 & 1 & - & 9 & 17 & 6 & 9 & 2 & - & - & 3 & 25 & 33 \\
\hline 2009 & - & - & 4 & 3 & 1 & - & 3 & 12 & 11 & 21 & - & - & 1 & - & 20 & 36 \\
\hline 2010 & - & - & 5 & 3 & 1 & 1 & 4 & 7 & 5 & 22 & - & - & 5 & 3 & 20 & 36 \\
\hline 2011 & - & - & 3 & 8 & 1 & 2 & 3 & 12 & 5 & 17 & - & - & 2 & 2 & 14 & 41 \\
\hline 2012 & - & - & - & - & - & 3 & 5 & 14 & 6 & 18 & - & - & 4 & 2 & 15 & 37 \\
\hline 2013 & - & - & 4 & 3 & 2 & - & 6 & 10 & 6 & 11 & - & - & 7 & 5 & 25 & 29 \\
\hline 2014 & - & 1 & 3 & 3 & 2 & - & 2 & 11 & 8 & 11 & - & - & 4 & 4 & 19 & 30 \\
\hline 2015 & - & - & 3 & 6 & - & - & 4 & 10 & 6 & 17 & - & 1 & 6 & 2 & 19 & 36 \\
\hline 2016 & 2 & 1 & 7 & 6 & - & - & 8 & 14 & 11 & 9 & - & - & 1 & 3 & 29 & 33 \\
\hline Total & 2 & 2 & 39 & 43 & 9 & 6 & 47 & 122 & 73 & 156 & 2 & 1 & 31 & 25 & 203 & 355 \\
\hline
\end{tabular}

Nota. Fonte: Dados da pesquisa.

Com base na Tabela 4, percebe-se a presença de autores de todas as regiões brasileiras e ainda a presença de 2 autoras e 1 autor que estão vinculados a IES estrangeiras. A região brasileira que apresenta menor número de autores é a do Norte, onde apenas 2 autores e 2 autoras publicaram. A região mais profícua é a Sul, onde há o maior número de autores homens (156) e mulheres (73). Além dela, a região Sudeste também se destaca no que concerne à produtividade acadêmica, com 47 mulheres e 122 homens. A região Nordeste destaca-se pela pequena disparidade entre homens (43) e mulheres (39). Ressalta-se que a região Centro-Oeste é a única região do Brasil onde o número de mulheres (9) é superior ao número de homens (6).

Os resultados referentes aos autores por região assemelham-se aos achados de Soares et al. (2014) e De Luca et al. (2011), em que os autores evidenciaram que as regiões Sul e Sudeste são as que apresentam maiores números de autoras. No entanto, enquanto tais autores apresentam a região Sudeste com número de autoras 
Análise da Produção Científica na Revista ABCustos: a participação feminina de 2006 a 2016

superior à região Sul, o presente estudo evidencia que a região Sul apresentou maior volume de autoras que a região Sudeste na produção sobre custos.

A Tabela 5 apresenta a abordagem dos artigos publicados na Revista ABCustos no decorrer dos anos analisados. Foram identificados artigos que contemplam as 3 diferentes abordagens metodológicas: quantitativa, qualitativa e quali-quantitativa.

Tabela 5

Abordagem dos artigos publicados na Revista ABCustos

\begin{tabular}{|c|c|c|c|c|c|c|c|c|c|c|c|c|}
\hline Abordagem & ஜ & 옹 & ్ֻ̊ & 옹 & 웅 & స్ & $\frac{N}{\text { N }}$ & $\frac{m}{i}$ & $\frac{\nabla}{\text { N }}$ & $\frac{10}{\delta}$ & $\frac{0}{\infty}$ & 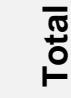 \\
\hline Quantitativa & 3 & 7 & 8 & 5 & 5 & 8 & 6 & 8 & 4 & 8 & 8 & 70 \\
\hline Qualitativa & 2 & 10 & 8 & 10 & 10 & 5 & 4 & 8 & 8 & 5 & 7 & 77 \\
\hline Quali-quantitativa & 1 & 1 & 2 & 3 & 3 & 4 & 6 & 1 & 3 & 2 & - & 26 \\
\hline Total & 6 & 18 & 18 & 18 & 18 & 17 & 16 & 17 & 15 & 15 & 15 & 173 \\
\hline
\end{tabular}

Nota. Fonte: Dados da pesquisa.

Evidencia-se que os artigos analisados utilizam de forma mais frequente a abordagem qualitativa (77) na condução dos estudos. O número de artigos com abordagem quantitativa (70) é inferior às pesquisas qualitativas, mas não apresenta uma grande discrepância em relação à outra abordagem. No que tange às pesquisas de abordagem quali-quantitativa, observa-se que esta abordagem apresentou o menor número de trabalhos, com 26 artigos publicados no periódico, divergindo dos achados de Oliveira e Aragão (2011), em que a abordagem quali-quantitativa aparece de forma mais frequente nas pesquisas sobre custos.

No que concerne às temáticas mais recorrentes nos estudos publicados na Revista ABCustos, a Tabela 6 forma uma lista dos temas. As temáticas são apresentadas de forma decrescente, do tema mais abordado aos que aparecem com menor frequência. 
Análise da Produção Científica na Revista ABCustos: a participação feminina de 2006 a 2016 Clayton Robson Moreira da Silva, Laís Vieira Castro Oliveira, Cinthya Rachel Firmino de Morais, Diego Sampaio Vasconcelos Ramalho Lima

Tabela 6

Temáticas mais abordadas nos artigos publicados na Revista ABCustos

\begin{tabular}{|c|c|c|c|c|c|c|c|c|c|c|c|c|}
\hline Temáticas mais abordadas & ঃి & స్ํ․ & 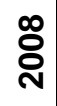 & 옹 & 웅 & స్ & $\frac{N}{\text { N }}$ & $\frac{m}{\text { N }}$ & $\frac{\nabla}{\text { D }}$ & $\frac{10}{2}$ & $\frac{0}{0}$ & $\begin{array}{l}\bar{\varpi} \\
\stackrel{0}{\circ}\end{array}$ \\
\hline Gestão de Custos & - & - & 1 & 1 & 4 & 2 & 3 & 3 & 4 & 1 & - & 19 \\
\hline Custos Aplicados ao Agronegócio & 2 & 2 & - & - & 1 & - & - & 1 & - & 5 & 3 & 14 \\
\hline Controladoria & - & 4 & 1 & 1 & 1 & 1 & 2 & 1 & 1 & - & - & 12 \\
\hline Método de Custeio ABC & - & - & 1 & 2 & 2 & 1 & 2 & - & 2 & 1 & 1 & 12 \\
\hline Estratégias em Custos & - & 2 & 2 & 2 & - & 1 & - & - & - & 3 & 1 & 11 \\
\hline Custos e/ou Contabilidade no Setor Público & 1 & - & 1 & 1 & 1 & - & 1 & 2 & - & - & 1 & 8 \\
\hline Análise/Viabilidade Econômico-Financeira & - & 1 & 1 & 1 & 1 & - & 1 & 1 & 1 & - & - & 7 \\
\hline Eficiência & - & 1 & 2 & - & 1 & 1 & - & - & - & - & 1 & 6 \\
\hline Ensino de Contabilidade de Custos & - & - & - & 1 & - & 1 & - & 1 & - & - & 3 & 6 \\
\hline Formação de Preços e Precificação & 1 & - & 1 & 1 & - & - & 1 & 1 & - & - & 1 & 6 \\
\hline Análise de Custos & - & - & - & - & - & - & - & 2 & 1 & - & 2 & 5 \\
\hline Custos e Gestão da Qualidade & - & - & 1 & 2 & - & - & - & - & - & 1 & - & 4 \\
\hline Custos Logísticos & - & - & - & 2 & - & 2 & - & - & - & - & - & 4 \\
\hline Orçamento & - & 1 & - & - & - & 1 & 1 & - & 1 & - & - & 4 \\
\hline Contabilidade Financeira & - & - & 1 & - & - & - & - & - & 1 & 1 & - & 3 \\
\hline Custos Ambientais & - & 1 & 1 & - & 1 & - & - & - & - & - & - & 3 \\
\hline Método UEP & - & - & - & 1 & - & - & - & - & 1 & - & 1 & 3 \\
\hline Teoria das Restrições & - & - & - & - & 2 & 1 & - & - & - & - & - & 3 \\
\hline Temas contemplados em 2 artigos ou menos & 2 & 6 & 5 & 3 & 4 & 6 & 5 & 5 & 3 & 3 & 1 & 43 \\
\hline Total & $\boldsymbol{0}$ & $\stackrel{\infty}{\sim}$ & $\stackrel{\infty}{\sim}$ & $\stackrel{\infty}{\infty}$ & $\stackrel{\infty}{\sim}$ & 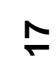 & $\stackrel{\bullet}{\circ}$ & 乏 & $\stackrel{2}{2}$ & $\stackrel{n}{2}$ & $\stackrel{n}{n}$ & $\Re^{m}$ \\
\hline
\end{tabular}

Nota. Fonte: Dados da pesquisa.

Com base na Tabela 6 , observa-se que a temática mais abordada no periódico é sobre Gestão de Custos, que aparece em 19 artigos. Esse achado converge com os estudos de Ribeiro e Santos (2016) e Carmo et al. (2014), que também evidenciaram o tema Gestão de Custos como o mais recorrente em pesquisas sobre Contabilidade de Custos. Além desse tema, outros também são evidenciados de forma recorrente em outros estudos, a saber: Análise/Viabilidade Econômico-Financeira (Walter, 2010); Método de Custeio ABC (Walter, 2010; Machado et al., 2012; Ribeiro \& Santos, 2016); Custos no Setor Público (Ribeiro \& Santos, 2016); Ensino de Contabilidade de Custos (Ribeiro \& Santos, 2016); Análise de Custos (Walter, 2010; Machado et al., 2012; Ribeiro \& Santos, 2016); Custos e Gestão da Qualidade (Machado et al., 2012; Ribeiro \& Santos, 2016); Custos Ambientais (Walter, 2010; Machado et al., 2012; Carmo et al., 
Análise da Produção Científica na Revista ABCustos: a participação feminina de 2006 a 2016

Clayton Robson Moreira da Silva, Laís Vieira Castro Oliveira, Cinthya Rachel Firmino de Morais, Diego

Sampaio Vasconcelos Ramalho Lima

2014/ Ribeiro \& Santos, 2016); Método UEP (Ribeiro \& Santos, 2016); entre outros temas com menor destaque.

Até então foram abordadas caraterísticas relacionadas ao perfil dos artigos, número de autores e gênero dos autores presentes no periódico em análise. Agora, farse-á uma análise voltada à vinculação dos autores a uma IES, além da identificação daqueles que mais publicaram na Revista $A B C$ ustos desde sua primeira edição.

Tabela 7

IES com maior número de autores que publicam no periódico

\begin{tabular}{|c|c|c|c|c|c|c|c|c|c|c|c|c|}
\hline $\begin{array}{l}\text { IES com maior número de } \\
\text { Autores(as) que publicam na } \\
\text { Revista ABCustos }\end{array}$ & ๕̊ & ఫ్ & ઠి & ઠ્ণ & 울 & $\overline{\tilde{N}}$ & సั. & $\stackrel{m}{\text { N }}$ & 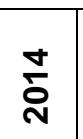 & 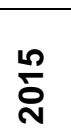 & $\stackrel{0}{\stackrel{0}{2}}$ & 嵒 \\
\hline UNISINOS & - & 3 & 3 & 4 & 4 & 6 & 2 & 9 & 3 & - & - & 34 \\
\hline UFSC & 2 & 2 & 2 & 7 & 5 & 2 & 5 & & 4 & 3 & 1 & 33 \\
\hline UFRJ & - & 5 & 2 & 1 & 3 & 6 & 2 & 2 & - & & 2 & 23 \\
\hline UFPR & 1 & 1 & 1 & - & 5 & 4 & 3 & - & 1 & 3 & 3 & 22 \\
\hline UFMG & 2 & & 1 & 5 & & - & 4 & 5 & - & 2 & 2 & 21 \\
\hline FURB & - & 2 & 1 & 2 & 4 & 1 & 1 & - & - & 3 & 4 & 18 \\
\hline UFU & - & - & - & - & - & 2 & - & - & 5 & 3 & 5 & 15 \\
\hline UNICENTRO & - & 1 & 3 & 3 & - & - & - & 1 & 2 & 3 & 2 & 15 \\
\hline USP & 2 & 2 & 5 & 2 & - & - & - & 1 & - & 1 & 2 & 15 \\
\hline UFC & - & 1 & 5 & 2 & - & - & - & - & - & - & 5 & 13 \\
\hline Estácio FIC & - & - & - & - & - & - & - & - & 5 & - & 6 & 11 \\
\hline UFBA & - & - & 3 & 1 & - & 4 & - & 3 & - & - & - & 11 \\
\hline UFPB & - & 1 & 1 & 2 & 4 & 1 & - & 2 & - & - & - & 11 \\
\hline UFPE & 3 & 1 & - & - & & 2 & - & - & 1 & 4 & - & 11 \\
\hline UFRGS & - & 1 & - & 3 & 5 & 1 & 1 & - & - & - & - & 11 \\
\hline Outras IES com 10 autores ou menos & 5 & 24 & 28 & 23 & 18 & 22 & 28 & 19 & 20 & 25 & 26 & 238 \\
\hline Autores sem Currículo Lattes & - & 2 & 3 & 1 & 8 & 4 & 6 & 12 & 8 & 8 & 4 & 56 \\
\hline Total & $\stackrel{2}{\sim}$ & \& & $\stackrel{\infty}{\circ}$ & டீ & i̊n & 吕 & กิ & เు & g & เก & ชิ & 员 \\
\hline
\end{tabular}

Nota. Fonte: Dados da pesquisa.

$\mathrm{Na}$ Tabela 7, pode-se evidenciar que a IES que tem maior número de autores vinculados nas publicações é a UNISINOS, com 34 autores. Além disso, observa-se que a UFSC aparece na segunda posição com apenas um autor a menos que a primeira (33). Nesse contexto, observa-se que há semelhança entre esse resultado com o de Ribeiro e Santos (2016), que registraram ser a UFSC a IES mais profícua na 
Análise da Produção Científica na Revista ABCustos: a participação feminina de 2006 a 2016

Clayton Robson Moreira da Silva, Laís Vieira Castro Oliveira, Cinthya Rachel Firmino de Morais, Diego

Sampaio Vasconcelos Ramalho Lima

produção de custos, seguida da UNISINOS. Além disso, Machado et al. (2012) também apresentam as IES UFSC e UNISINOS em posição de destaque, abaixo apenas da USP, que aparece como IES de destaque em outros estudos como os de Walter (2010)

e Reis et al. (2012).

Tabela 8

Autores que mais publicaram na Revista ABCustos

\begin{tabular}{l|c|c|c|c|c}
\hline \multicolumn{1}{c|}{ Nome } & Gên. & Região & IES & Titulação & No Artigos \\
\hline Jorge Eduardo Scarpin & H & Sul & UFPR & Doutor & 10 \\
\hline Antonio Artur de Souza & $\mathrm{H}$ & Sudeste & UFMG & Doutor & 8 \\
\hline Marcos Antonio de Souza & $\mathrm{H}$ & Sul & UNISINOS & Doutor & 7 \\
\hline Clovis Antônio Kronbauer & $\mathrm{H}$ & Sul & UNISINOS & Doutor & 6 \\
\hline Ilse Maria Beuren & $\mathbf{M}$ & Sul & UFSC & Doutora & $\mathbf{5}$ \\
\hline Charles Washington Costa de Assis & $\mathrm{H}$ & Nordeste & Estácio/FIC & Esp. & 4 \\
\hline Ewerton Alex Avelar & $\mathrm{H}$ & Sudeste & UFMG & Mestre & 4 \\
\hline Marcelo Alvaro da Silva Macedo & $\mathrm{H}$ & Sudeste & UFRJ & Doutor & 4 \\
\hline Rita de Cassia Fonseca & $\mathbf{M}$ & Sul & UNICENTRO & Mestra & $\mathbf{4}$ \\
\hline Rosângela Venâncio Nunes & $\mathbf{M}$ & Nordeste & Estácio/FIC & Mestra & $\mathbf{4}$ \\
\hline Alessandra Vasconcelos Gallon & $\mathbf{M}$ & Nordeste & UFC & Doutora & $\mathbf{3}$ \\
\hline Antonio André Cunha Callado & $\mathrm{H}$ & Nordeste & UFRPE & Doutor & 3 \\
\hline Fabiano Maury Raupp & $\mathrm{H}$ & Sul & UDESC & Doutor & 3 \\
\hline Fabricia Silva da Rosa & $\mathbf{M}$ & Sul & UFSC & Doutora & $\mathbf{3}$ \\
\hline Franciane Luiza Salamoni & $\mathbf{M}$ & Sul & SENAC & Mestra & $\mathbf{3}$ \\
\hline Josir Simeone Gomes & $\mathrm{H}$ & Sudeste & UNIGRANRIO & Doutor & 3 \\
\hline Joyce Menezes da Fonseca Tonin & $\mathbf{M}$ & Sul & UFPR & Mestra & $\mathbf{3}$ \\
\hline Juliana Pinto & $\mathbf{M}$ & Sul & FURB & Mestra & $\mathbf{3}$ \\
\hline Leopoldo Pedro Guimarães Filho & $\mathrm{H}$ & Sul & UNESC & Doutor & 3 \\
\hline Maria Silene Alexandre Leite & $\mathbf{M}$ & Nordeste & UFPB & Doutora & $\mathbf{3}$ \\
\hline Mariana Guerra & $\mathbf{M}$ & C. Oeste & UnB & Doutora & $\mathbf{3}$ \\
\hline Nayana de Almeida Adriano & $\mathbf{M}$ & Nordeste & Estácio/FIC & Mestra & $\mathbf{3}$ \\
\hline Rogério João Lunkes & $\mathrm{H}$ & Sul & UFSC & Doutor & 3 \\
\hline Terence Machado Boina & $\mathbf{H}$ & Sudeste & UFRJ & Esp. & 3 \\
\hline Valmor Slomski & $\mathbf{H}$ & Sudeste & USP & Doutor & 3 \\
\hline
\end{tabular}

Nota. Fonte: Dados da pesquisa.

Foi elaborada uma lista com os autores que mais publicaram na Revista ABCustos, desde sua primeira edição. Foram considerados os autores com 3 publicações ou mais para compor a lista. Com base na Tabela 8, observa-se que a maioria dos autores que mais publicaram são do gênero masculino, indo ao encontro 
Análise da Produção Científica na Revista ABCustos: a participação feminina de 2006 a 2016 Clayton Robson Moreira da Silva, Laís Vieira Castro Oliveira, Cinthya Rachel Firmino de Morais, Diego

Sampaio Vasconcelos Ramalho Lima

dos estudos de Souza e Rasia (2011) e Santos (2015), que também verificaram maior volume de homens em relação às mulheres que mais publicaram nas edições do Congresso Brasileiro de Custos.

No que tange às mulheres que mais publicaram na Revista $A B C$ ustos, Ilse Maria Beuren figura como a mulher mais profícua, estando abaixo de quatro autores do gênero masculino. Essa autora também ocupa posição de destaque em outros estudos como o de Barboza et al. (2015), onde figura como a autora que mais publicou estudos bibliométricos na história do Congresso Brasileiro de Custos, e no estudo de Nascimento et al. (2014), onde a autora ocupa a segunda posição entre os autores que mais publicaram sobre custeio alvo no Congresso Brasileiro de Custos.

Em relação ao perfil das mulheres presentes na Tabela 8, observou-se que 6 delas são mestras e 5 são doutoras. Além disso, 6 delas são da região Sul, 4 são da região Nordeste e 1 da região Centro-Oeste. Nenhuma das mulheres que compõem a lista das que mais publicaram na Revista $A B C$ ustos é das regiões Norte e Sudeste. Verifica-se ainda que apenas 3 das mulheres que mais publicaram no periódico têm volume de produções superior a 3 artigos.

\section{CONSIDERAÇÕES FINAIS}

O objetivo do trabalho foi analisar a participação feminina na produção científica sobre custos na Revista ABCustos e, adicionalmente, verificou-se o perfil dos artigos publicados no periódico. Com base na pesquisa e nos resultados obtidos, é possível traçar algumas considerações quanto à participação feminina na produção científica sobre custos. Dessa forma, o estudo contribuiu com a reflexão acerca da participação feminina na área de custos, cujo crescimento é visível na área acadêmica, entretanto, a participação feminina ainda é significativamente pequena em relação à participação de autores do gênero masculino, apesar da ampliação do gênero feminino nos níveis mais elevados de ensino. 
Análise da Produção Científica na Revista ABCustos: a participação feminina de 2006 a 2016 Clayton Robson Moreira da Silva, Laís Vieira Castro Oliveira, Cinthya Rachel Firmino de Morais, Diego

Sampaio Vasconcelos Ramalho Lima

A pesquisa permitiu constatar que o número de artigos de autoria mista (105) é superior ao número de artigos apenas com homens (55). Porém, observa-se ainda uma acentuada diferença entre o total de artigos apenas com mulheres (13) e os demais arranjos (masculinos e mistos). Tais resultados possibilitam maior entendimento e compreensão de como a temática de Custos é desenvolvida, trabalhada, divulgada e socializada pelos sujeitos envolvidos com essa temática, contribuindo com 0 crescimento deste assunto na produção científica do periódico em análise. Dessa forma, constatou-se que o número de mulheres que publicam no periódico é inferior ao número de homens.

No que concerne à quantidade de autores por artigo, observou-se que os trios são mais frequentes, estando esse arranjo presente em 63 artigos. A região mais profícua é a Sul, onde há o maior número de autores homens (156) e mulheres (73). Além dela, a região Sudeste também se destaca no que tange à produtividade acadêmica, com 47 mulheres e 122 homens. A região Nordeste destaca-se pela pequena disparidade entre homens (43) e mulheres (39). Ressalta-se que a região Centro Oeste é a única região do Brasil onde o número de mulheres (9) é superior ao número de homens (6).

De maneira geral, a pesquisa evidenciou que os procedimentos metodológicos qualitativos são os mais desenvolvidos pelos autores. Em relação às temáticas mais recorrentes nos estudos publicados na Revista ABCustos, destacou-se o tema Gestão de Custos, figurando em 19 artigos. Em relação ao vínculo dos autores, foi observado que a IES que tem maior número de autores vinculados nas publicações é a UNISINOS, com 34 autores. Além disso, observa-se que a UFSC aparece na segunda posição com apenas um autor a menos que a primeira (33). Por fim, no que tange às mulheres que mais publicaram na Revista ABCustos, llse Maria Beuren figura como a mulher mais profícua, estando abaixo de quatro autores do gênero masculino.

Os resultados contemplados neste artigo permitiram realizar um mapeamento da produção científica de um periódico nacional, ensejando a reflexão acerca da participação feminina na pesquisa científica sobre custos. Com base nisso, 
Análise da Produção Científica na Revista ABCustos: a participação feminina de 2006 a 2016

Clayton Robson Moreira da Silva, Laís Vieira Castro Oliveira, Cinthya Rachel Firmino de Morais, Diego

Sampaio Vasconcelos Ramalho Lima

compreende-se, portanto, que a participação feminina ainda é tímida em relação à participação do gênero masculino, mesmo tendo ocorrido uma ampliação nos últimos anos. São relevantes também as disparidades de participação entre as regiões, podendo este achado estar associado às desigualdades no contexto acadêmico entre as regiões, já que as duas regiões (Sul e Sudeste) concentram uma maior quantidade de programas de pós-graduação stricto sensu nas áreas de Administração e Ciências Contábeis.

Em relação à limitação do trabalho, este estudo teve como foco o periódico nacional ABCustos, contudo, existe a possibilidade de ampliar a pesquisa focando outros periódicos nacionais e internacionais. Para estudos futuros, recomenda-se uma análise incluindo periódicos nacionais e internacionais, em que se possa compreender com maior detalhe a evolução da participação feminina na produção científica na área de custos.

\section{REFERÊNCIAS}

ABCustos. (2017). Políticas Editoriais. Disponível em: https://www.abcustos.emnuvens.com.br/abcustos. Acesso em: 15/junho/2017.

Araújo, E. A. T. \& Silva, W. A. C. (2010). Pesquisa científica em contabilidade gerencial nos EnANPADs de 2003 a 2008. Revista Universo Contábil, 6(3), 29-44.

Barboza, M. M., Sousa, W. D., Nascimento, J. C. H. B., Bernardes, J. R., \& Santos, J. S. (2015). O Perfil da Pesquisa Bibliométrica Publicada nas 19 Edições do Congresso Brasileiro de Custos. ABCustos, 10(2), 87-117.

Bardin, L. (2009). Análise de conteúdo. São Paulo: Edições 70.

Baylão, A. L. S. \& Schettimo, E. M. O. (2014). A inserção da mulher no mercado de trabalho brasileiro. Anais do Simpósio de Excelência em Gestão e Tecnologia, Resende, RJ, Brasil, 11.

Cappelle, M. C. A., Brito, M. J., Melo, M. C. O. L., \& Vasconcelos, K. A. (2007). A produção científica sobre gênero nas organizações: uma meta-análise. Revista Eletrônica de Administração, 13(3), 502-528. 
Análise da Produção Científica na Revista ABCustos: a participação feminina de 2006 a 2016 Clayton Robson Moreira da Silva, Laís Vieira Castro Oliveira, Cinthya Rachel Firmino de Morais, Diego

Sampaio Vasconcelos Ramalho Lima

Carmo, C. R. S., Xavier, L. V., Pereira, V. S., \& Martins, V. F. (2014). O perfil das pesquisas sobre contabilidade gerencial e contabilidade de custos na pós-graduação Stricto sensu da FEA-USP a partir de um recorte temporal de 1998 a 2011. Revista de Administração e Contabilidade, 6(1), 70-87.

Casa Nova, S. P. C. (2012). Impactos de mestrados especiais em contabilidade na trajetória de seus egressos: um olhar especial para gênero. Revista de Contabilidade e Controladoria, 4(3), 37-62.

Centro de Gestão e Estudos Estratégicos [CGEE]. (2016). Mestres e Doutores 2015: estudos da demografia da base técnico-científica brasileira. Recuperado de: https://www.cgee.org.br/documents/10182/734063/Mestres_Doutores_2015_Vs3.pdf. Acesso em: 25/junho/2017.

Coelho, E. C. (2015). Gênero e inserção acadêmica: um estudo com ênfase em doutoras em contabilidade. (Dissertação de mestrado). Pontifícia Universidade Católica de São Paulo - PUCSP, São Paulo, SP, Brasil.

Collis, J. \& Hussey, R. (2005). Pesquisa em administração: um guia prático para alunos de graduação e pós-graduação. (2a ed.). Porto Alegre: Bookman.

Conselho Federal de Contabilidade [CFC]. (2014). Mulher Contabilista. Recuperado em 15 maio, 2017, de http://www.portalcfc.org.br/projetos/mulher_contabilista/.

Conselho Federal de Contabilidade [CFC]. (2017). Presidentes. Recuperado em 23 junho, 2017, de

http://www.portalcfc.org.br/o_conselho/presidentes/presidente.php?id=3916.

Crepaldi, S. A. (2010). Curso básico de contabilidade de Custos (5a ed.). São Paulo: Atlas.

Cruz, C., Marques, A., Slilva, R., \& Cogan, S. (2010) Teoria das Restrições: Um Estudo Bibliométrico da Produção Científica Apresentada no Congresso Brasileiro de Custos (1994-2008). Revista ABCustos, 5(1), 152-175.

Cunha, M. B., Peres, O. M. R., Giordan, M., Bertoldo, R. R., Marques, G. Q., \& Duncke, A. C. (2014). As mulheres na ciência: o interesse das estudantes brasileiras pela carreira científica. Educación Química, 25(4), 407-417.

Cunha, L. C. \& Kremer, A. W. (2013, novembro). O perfil da bibliografia nos planos de ensino das disciplinas de custos nos cursos de Ciências Contábeis do Brasil. Congresso Brasileiro de Custos, Uberlândia, MG, Brasil, 20.

De Luca, M. M. M., Gomes, C. A. S., Corrêa, D. M. M. C., \& Domingos, S. R. M. (2011). Participação Feminina na Produção Científica em Contabilidade Publicada nos Anais 
Análise da Produção Científica na Revista ABCustos: a participação feminina de 2006 a 2016

Clayton Robson Moreira da Silva, Laís Vieira Castro Oliveira, Cinthya Rachel Firmino de Morais, Diego

Sampaio Vasconcelos Ramalho Lima

dos Eventos EnANPAD, Congresso USP de Controladoria e Contabilidade e Congresso ANPCont. Revista de Contabilidade e Organizações, 5(11), 145-164.

Exame Nacional de Desempenho de Estudantes [ENADE]. (2012). Relatório Síntese Ciências Contábeis. Recuperado em 25 junho, 2017, de http://download.inep.gov.br/educacao_superior/enade/relatorio_sintese/2012/2012_rel_ ciencias_contabeis.pdf.

Fernandes, V., Gomes, D., \& Ribeiro, J. L. (2016). A contabilidade, o acesso e o exercício da profissão de contabilista certificado/a na perspectiva das mulheres. Revista Ex Aequo, (33), 49-65.

Ferrari, P. S., Camacho, R. R., Rodrigues, A. F. R. F., Marroni, C. H. M. H., \& Panosso, A. (2012). Análise da produção científica do Congresso Brasileiro de Custos, na área de Ensino e Pesquisa em contabilidade no período de 1989 a 2009. Congresso Brasileiro de Custos, Bento Goncalves, RS, Brasil, 19.

Giuliano, P. (2014). The Role of Women in Society: from Preindustrial to Modern Times. CESifo Economic Studies, 61(1), 33-52.

Gray, D. E. (2012). Pesquisa no mundo real (2a ed.). Porto Alegre: Penso.

Hofer, E., Pacheco, V., Souza, A., \& Protil, R. B. (2011). A relevância do controle contábil para o desenvolvimento do agronegócio em pequenas e médias propriedades rurais. Revista de Contabilidade e Controladoria, 3(1), 27-42.

Hukai, D. \& Li, J. (2009). The underrepresentation of women in accounting academia. Academy of Accounting and Financial Studies Journal, 13(Ed. Especial).

Instituto Brasileiro de Geografia e Estatística [IBGE]. (2008). Algumas características da inserção das mulheres no mercado de trabalho. Recuperado em 25 junho, 2017, de https://www.ibge.gov.br/home/estatistica/indicadores/trabalhoerendimento/pme_mulher/ Suplemento_Mulher_2008.pdf.

Lemos Júnior, L. C., Santini, R. B., \& Silveira, N. S. P. (2015). A Feminização da Área Contábil: um estudo qualitativo básico. Revista de Educação e Pesquisa em Contabilidade, 9(1), 64-83.

Machado, D. G., Silva, T. P. \&, Beuren, I. M. (2012). Produção científica de custos: análise das publicações em periódicos nacionais de contabilidade sob a perspectiva das redes sociais e da bibliometria. Contabilidade, Gestão e Governança, 15(3), 3-16.

Macias-Chapula, C. A. (1998). O papel da informetria e da cienciometria e sua perspectiva nacional e internacional. Ciência da Informação, 27(2), 134-140. 
Análise da Produção Científica na Revista ABCustos: a participação feminina de 2006 a 2016

Clayton Robson Moreira da Silva, Laís Vieira Castro Oliveira, Cinthya Rachel Firmino de Morais, Diego

Sampaio Vasconcelos Ramalho Lima

Megliorini, E. (2012). Custos: análise e gestão. (3a ed.). São Paulo: Pearson Prentice Hall.

Michels, C. \& Schmoch, U. (2014). Impact of bibliometric studies on the publication behaviour of authors. Scientometrics, 98(1), 369-385.

Moraes Júnior, V. F., Araújo, A. O., \& Rezende, I. C. C. (2013). Estudo bibliométrico da área ensino e pesquisa em gestão de custos: triênio 2007-2009 do congresso Brasileiro de custos. Revista de Administração, Contabilidade e Sustentabilidade, 3(2), 20-38.

Morais, C. R. F., Cabral, A. C. A., Santos, S. M., Pessoa, M. N. M., \& Oliveira, L. V. C. (2016) A participação feminina na produção científica nas áreas de administração e ciências contábeis. Congresso de Administração, Sociedade e Inovação, Juiz de Fora, MG, Brasil, 9.

Nascimento, J. C. H. B., Bernardes, J. R., Sousa, W. D., Pinheiro, L. V. S., \& Castro, M. B. M. B. (2014). Análise da progressão do conhecimento sobre custeio alvo: uma análise bibliométrica dos artigos apresentados nas 19 edições do Congresso Brasileiro de Custos. Custos e @gronegócio Online, 10(3), 350-373.

Oliveira, A. C. P. \& Aragão, I. R. B. N. (2011). Pesquisa em contabilidade de custos: um estudo sobre características dos artigos publicadas nas revistas on-line Brasileiras avaliadas pela Coordenação de Aperfeiçoamento de Pessoal de Nível Superior. Revista de Administração e Contabilidade, 3(2), 41-56.

Pinheiro Neto, G. F., Mapurunga, A. N. V., \& Santos, S. M. (2010). Marys dos Estudos Organizacionais. Encontro de Estudos Organizacionais da ANPAD, Florianópolis, SC, Brasil, 6.

Pinto, A. L., Efrain-García, P., Barquín, B. A. R., \& González, J. A. M. (2007). Indicadores científicos na literatura em bibliometria e cientometria através das redes sociais. Brazilian Journal of Information Science, 1(1), 58-76.

Portal Brasil. (2016). Mulheres são maioria da população e ocupam mais espaço no mercado de trabalho. Recuperado em 25 junho, 2017, de http://www.brasil.gov.br/cidadania-e-justica/2015/03/mulheres-sao-maioria-dapopulacao-e-ocupam-mais-espaco-no-mercado-de-trabalho.

Ramos, L., Aguas, M. F. F., \& Furtado, L. M. S. (2011). Participação Feminina na Força de Trabalho Metropolitano: o papel do status socioeconômico das famílias. Economia Aplicada, 15(4), 595-611.

Reis, J. A. F., Cruz, J. A. W., Rocha, D. T., \& Souza, A. (2012). Custos: perspectivas e tendências da produção científica. Pensar Contábil, 14(55), 4-13. 
Análise da Produção Científica na Revista ABCustos: a participação feminina de 2006 a 2016 Clayton Robson Moreira da Silva, Laís Vieira Castro Oliveira, Cinthya Rachel Firmino de Morais, Diego

Sampaio Vasconcelos Ramalho Lima

Resende, M. C. R., Ramos, M. A., Melo, A. A. O., Tomaz, C. M., Pacheco, M. H. S., \& Silva, W. A. C. (2012). Participação feminina na produção científica em finanças nos Enanpads de 2000 a 2010. Revista Ciências Sociais em Perspectiva, 11(20), 1-22.

Ribeiro, H. C. M. \& Santos, M. C. (2016). Produção acadêmica em seu estado da arte do tema custos divulgada nos periódicos da área contábil de 2010 a 2014. ConTexto, 16(33), 90-112.

Ribeiro, H. C. M. \& Tavares, V. C. M. (2017). Comportamento e Particularidades da produção acadêmica do tema "Contabilidade Gerencial" divulgada na base de dados do ISI WEB of Science Core Collection de 1985 a 2014. Revista de Educação e Pesquisa em Contabilidade, 11(1), 5-29.

Richardson, R. J. (2008). Pesquisa social: métodos e técnicas. (3a ed.). São Paulo: Atlas.

Rocha, I., Wienhage, P., \& Scarpin, J. E. (2010). Investigação da produção científica relacionada ao custeio-meta e custeio kaizen no período de 2002 a 2009. ConTexto, 10(18), 75-86.

Santos, G. C. (2015). Análise Bibliométrica dos Artigos Publicados como Estudos Bibliométricos na História do Congresso Brasileiro de Custos. Pensar Contábil, 17(62), $4-13$.

Santos, V. M. (2010). Ciência e Tecnologia: expressões sutis da discriminação de gênero? Emancipação, 10(2), 459-477.

Scharf, L., Borgert, A., \& Richartz, F. (2011). Análise estatística dos custos indiretos de produção: uma contribuição ao estudo do "custo exato". Revista de Contabilidade e Organizações, 5(12), 135-156.

Silva Júnior, C. P. \& Martins, O. S. (2017). Mulheres no Conselho Afetam o Desempenho Financeiro? Uma Análise da Representação Feminina nas Empresas Listadas na BM\&FBOVESPA. Sociedade, Contabilidade e Gestão, 12(1), 62-76.

Silva, C. N., Anzilago, M., \& Lucas, A. C. (2015). A Mulher Contabilista nas Publicações Acadêmicas Brasileiras. Anais do Congresso USP de Controladoria e Contabilidade, São Paulo, SP, Brasil, 15.

Silva, M. Z. \& Beuren, I. M. (2015). Contabilidade gerencial em hospitais: análise bibliométrica de artigos publicados no período 1950 a 2011. Alcance, 22(1), 80-104.

Siqueira, I. P., Melz, L. J., Santos, J. S. C., \& Torres, A. L. (2013). A inserção da mulher como profissional contábil nos escritórios de contabilidade de Tangará da Serra-MT. Revista UNEMAT de Contabilidade, 2(3), 138-153. 
Análise da Produção Científica na Revista ABCustos: a participação feminina de 2006 a 2016 Clayton Robson Moreira da Silva, Laís Vieira Castro Oliveira, Cinthya Rachel Firmino de Morais, Diego Sampaio Vasconcelos Ramalho Lima

Soares, M. de N. M., Lessa, B. S., Cabral, A. C. A., Pessoa, M. N. M., \& Santos, S. M. (2015). A participação feminina nos estudos sobre estratégia. Revista Raunp, 7(1), 2537.

Souza, M. A. \& Rasia, K. A. (2011). Custos no agronegócio: um perfil dos artigos publicados nos Anais do Congresso Brasileiro de Custos no período de 1998 a 2008. Contabilidade, Gestão \& Governança, 14(1), 69-81.

Vilela, C. V. F. (2015). O acesso das mulheres ao estudo da Contabilidade: comparação entre o caso britânico e o caso português. (Dissertação de mestrado). Instituto Superior de Contabilidade e Administração do Porto, Porto, Portugal.

Walter, F. (2010). O perfil dos artigos publicados no Custos e @gronegócio Online. Custos e @gronegócio on line, 6(3), 156-175.

Data de Submissão: 27/06/2017

Data de Aceite: 30/05/2018 